ISSN 0103-7013

Psicol. Argum., Curitiba, v. 28, n. 61, p. 167-174 abr./jun. 2010

Licenciado sob uma Licença Creative Commons

\title{
ALGUMAS CONSIDERAÇÕES SOBRE A CONSTITUIÇÃO PSÍQUICA
}

\author{
Some considerations about the psychic constitution
}

\section{Paulina Schmidtbauer Rocha}

Linguista, psicanalista, sócia fundadora do Centro de Pesquisa em Psicanálise e Linguagem e do Círculo Psicanalítico de Pernambuco, Recife, PE - Brasil, paulinarocha@uol.com.br

\section{Resumo}

A partir de uma série de cenas do cotidiano e da clínica psicanalítica, a autora analisa o surgimento do acontecer psíquico em bebês e crianças pequenas, articulando-o ao conceito de rede tensional libidinal grupal. O artigo demonstra como o sentimento de Eu depende dos outros do ambiente e do compartilhamento de experiências significativas em que cada um tem uma participação ativa. Trata-se, pois, de um momento em grupo, mas no qual a participação de cada um dos integrantes é vivida tanto de modo particular quanto grupal. Além disso, o trabalho destaca a precocidade desse acontecer psíquico para as crianças. Comenta então o uso desse conceito no trabalho clínico com crianças em grave sofrimento psíquico.

Palavras-chave: Acontecer psíquico. Rede tensional libidinal grupal. Clínica psicanalítica. Crianças pequenas. Autismo.

\begin{abstract}
Based on a sequence of scenes of daily life and of psychoanalytic clinic, the author discusses the emergence of the mental functioning in babies and little children, to articulate it to the concept of group libidinal tensional net. The article demonstrates how the sense of Ego depends on the others, the environment and the exchanges of the significative experiences in which each one has an active participation. It is a moment in group, but the participation of each one of the elements is lived in a way that is both singular and collective. Therefore, the author signs the precocity of this psychic process to the children and comments the use of this concept at the clinic work with children with psychic suffering.
\end{abstract}

Keywords: Mental functioning. Group libidinal tensional net. Psychoanalytic clinic. Little children. Autism. 
Presenciei nesses últimos quinze anos, em vários momentos dentro do setting psicanalítico e fora dele, na vida cotidiana, cenas que a posteriori se agruparam, se revestiram de sentidos e clarearam alguns aspectos do acontecer psíquico tal qual exposto por Freud ([1911] 2004), no seu artigo "Formulações sobre dois princípios do acontecer psíquico".

Minhas preocupações com a constituição psíquica, ou melhor, de me apropriar da expressão de Freud "acontecer psíquico", estão marcadas pela atuação clínica com crianças em sofrimento psíquico precoce e com a clínica psicanalítica das psicoses ao que se acrescenta uma preocupação com a clínica psicanalítica do social. Consequentemente, preocupei-me com as capacidades humanas de viver e trabalhar em grupo.

Porque criamos ao longo da vida vários grupos? De onde provêm a sensibilidade, a necessidade do coletivo? Vejamos o que Freud nos diz no seu livro Psicologia das massas e análise do Eu:

[...] O contraste entre a psicologia individual e a psicologia social ou de grupo, que à primeira vista pode parecer pleno de significação, perde grande parte de sua nitidez quando examinado mais de perto. É verdade que a psicologia individual relaciona-se com o homem tomado individualmente e explora os caminhos pelos quais ele busca encontrar satisfação para seus impulsos instintuais; contudo, apenas raramente e sob certas condições excepcionais, a psicologia individual se acha em posição de desprezar as relações desse indivíduo com os outros. Algo mais está invariavelmente envolvido na vida mental do indivíduo, como um modelo, um objeto, um auxiliar, um oponente, de maneira que, desde o começo, a psicologia individual, neste sentido ampliado, mas inteiramente justificável das palavras é, ao mesmo tempo, também psicologia social (FREUD, [1920] 1996, p. 91).

Podemos partir da constatação de que nunca estamos sós, sempre estamos entre vários. Gostaria de esclarecer que este termo "vários" me parece apropriado 1 , porque traz a ideia de múltiplos, diversos, mutáveis. Organizamo-nos psiquicamente para viver e produzir em grupo, sem que por isso percamos a singularidade, mas tampouco a perspectiva do coletivo. Isso, até na atualidade, quando está privilegiada a ação do "um", o crescimento do "um", ou então, a negação da singularidade e, consequentemente, do grupo enquanto composto de vários, quando o "vários" vira uma massa (torcidas organizadas).

Mesmo se em muitas teorizações psicanalíticas sobre os primeiros tempos da existência humana, esse aspecto mencionado por Freud fora esquecido, gostaria de pensá-los desde a vida intrauterina em interação com o meio ambiente e considerar que assim se estendem vida afora. Digamos, vida cheia de acontecimentos que implicam o bebê ele mesmo e os outros, aqueles que esperaram por alguns meses sua chegada. A criança, ao nascer, está aguardando um grupo, na expectativa das múltiplas sonoridades, inscrições sonoras registradas ainda durante a vida intrauterina. O sentido tátil e auditivo está maduro antes de o bebê nascer, ele registra as vozes do meio ambiente e os sons do corpo materno; as batidas do coração, a própria voz da mãe. Essa variedade e diversidade sonora, já presente nos traços mnêmicos do bebê, além dos registros das sensações táteis, vai fazer parte da sua experiência ao vir ao mundo. Ouvilas, senti-las ao nascer avivará as inscrições e assim o bebê vai reencontrá-las neste novo ambiente, com algumas modificações, todavia reconhecíveis. Assim se daria continuidade da sua existência. Observando nas salas de parto, percebemos que ao ser colocado no peito da mãe, o bebê reencontra essas sonoridades e fica plácido. Muito devagar começa a procurar a fonte sonora tentando focalizar e agrupar-se com o olhar. Vejamos o que diz Freud ([1911]2004, p. 66):

[...] Foi preciso que não ocorresse a satisfação esperada, que houvesse uma frustração para que essa tentativa de satisfação pela via alucinatória fosse abandonada. Em vez de alucinar, o aparelho psíquico teve então de se decidir

1 Adjetivo pertencente a uma pluralidade de espécies, ou apresentando diferentes cores, formas, etc.; sortido, variado, caracterizado pela diversidade, que abrange diversas manifestações; múltiplo; que não é constante; volúvel, instável; que não sossega; buliçoso, irrequieto; que hesita; indeciso, incerto, irresoluto; sem coerência; contraditório, incongruente, discrepante; pronome indefinido que, no uso adjetivo, indetermina o substantivo, quando a ele anteposto, e no uso substantivo, o substitui, sempre indicando pluralidade, mas não totalidade; diversos, alguns, muitos, numerosos. 
por conceber as circunstancias reais presentes no mundo externo e passou a almejar uma modificação real deste. Com isso foi introduzido um novo princípio da atividade psíquica: não mais era imaginado o que fosse agradável, mas sim o real, mesmo em se tratando de algo desagradável. Essa instauração do princípio da realidade mostrou-se um passo de importantes conseqüências.

E mais adiante no próprio texto continua:

[...] A realidade exterior adquiriu maior importância, e com isso também se tornou mais relevante o papel dos órgãos sensoriais voltados para o mundo externo e da consciência a eles ligada. [...] constituiu-se uma função especial, a atenção que deveria fazer uma busca periódica no mundo externo para que os dados fossem conhecidos de antemão caso uma necessidade interna inadiável se manifestasse (FREUD, [1911] 1996, p. 66).

Então é possível perceber que Freud leva em consideração o encontro entre o bebê e o mundo externo como fundamental para o acontecer psíquico. Winnicott (1978) dirá mais tarde que o meio ambiente apresenta o mundo para o bebê. Assim, parece-me que ele está bem condizente e, ao mesmo tempo, se situa na continuação do pensamento de Freud.

Essas observações e as leituras dos textos de Sonia Salmeron (1996a, b) ajudam a entender os primórdios da constituição do eu, e seguindo esta autora colocam em evidência a importância do grupo, ou de vários, na constituição do que ela, Kaës (1976) e Anzieu (1976) chamaram de Eu grupal. Mas Salmeron $(1996 a, b)$ traz algumas contribuições a mais para a compreensão da constituição da noção do coletivo.

Ela complementa dizendo que, por sua vez, o nascimento de um bebê desencadeia as expectativas no grupo familiar, ou naqueles que estão ao redor da gestante, com todas as fantasias e projeções. Essa expectativa estabelece com o recém-nascido, esse novo que chegou, uma relação privilegiada, e no trabalho clínico é visível que cada pessoa ao redor desse bebê acredita inconscientemente ser o principal personagem para ele, que é amado "bem mais e melhor" que todos os outros. Essa fantasia dos vários, sejam ou não membros do grupo familiar, estará na base da vitalidade de um recém-nascido.
O bebê é vivido fantasmaticamente como um bebê maravilhoso, um tesouro que estabelece no grupo uma dinâmica, que Sônia Salmeron (1996b) chama de "dinâmica tensional libidinal grupal". Como ela diz, daí vai nascer uma política de grupo, uma diplomacia de grupo. Basta lembrar todos os movimentos que acontecem entre os avôs, as tias, os pais, os bisavós, os ciúmes, afetos, conselhos, medos, etc. Tudo isso coexiste nas relações inconscientes e até mesmo nas nossas relações conscientes. Um exemplo disso é o desejo que os pais têm de que seus filhos sejam amados por todos. Pode ser por razões narcísicas, por razões generosas, ou por razões mais políticas: às vezes como proteção às crianças (por exemplo, quando os pais morrem, para ter alguém que cuide do filho deles) ou, por razão bem banal, quando eles desejam algumas horas de paz, ter alguém que acolha a criança com satisfação para brincar com ela. Todas essas razões resumem-se no desejo de que o filho seja amado no grupo ao qual pertence. O padrinho e a madrinha na nossa cultura católica, afirma Salmeron (1996b), não é outra coisa a não ser uma forma de assegurar que na ausência dos pais alguém cuidará do filho, o que é também ligado à angústia de perda do objeto. Ao redor da criança forma-se o que Salmeron (1996b) chama de "rede tensional libidinal grupal".

Quanto à criança, ela vai adotar inconscientemente esses modos de relacionamento familiar, vai estabelecer a relação com cada membro do grupo. Esse movimento grupal, essa rede tensional libidinal traz também as tensões entre os membros do grupo, entre si e em relação ao bebê. Os modos de relações naquela família e as tensões que aqui entram em jogo vão fazer parte da experiência do bebê. Assim, estarão na base do que Sônia Salmeron (1996a) chama “o ego grupal”, cuja função será de formar no futuro outros grupos, exatamente por ter havido essa experiência.

Dessa rede faz parte aquele que cuida de uma forma privilegiada do bebê. Durante bastante tempo, essa relação, chamada relação dual, foi privilegiada nas formulações dos psicanalistas que pareciam esquecer-se da existência dos vários que fazem parte do ambiente e que estão presentes ao mesmo tempo. Assim, formulou-se a ideia de que a presença do pai era algo mais tardio, como também o grupo.

Freud dizia que o eu era resultado, era o depósito de diferentesidentificações vividas nainfância, de certo modo, um grupo, mas aqui se tratam 
de identificações secundárias. As identificações do sistema primário, através das sonoridades das vozes, dos contatos físicos, formaram um grupo de identificações primárias interno.

Nas suas formulações, Freud ([1920] 1996) destacou no início das suas elaborações ideal do eu, eu ideal, e o super eu. Mas não definiu bem, deixou relativamente esfumaçadas as fronteiras entre ideal do eu e eu ideal e não avançou nas concepções sobre o grupo.

Sonia Salmeron (1996a) fala de maneira bem interessante da formação do eu ideal e do ideal do eu. O primeiro seria resultado de uma relação arcaica com uma personagem onipotente, a mãe, nascendo da identificação primária com a onipotência materna. O eu ideal fica também ligado a essa identificação com a mãe que, lembrando Melanie Klein (1981), é dona no seu ventre de um número incalculável de bebês, ela tem nela um grupo.

Salmeron lembra que o bebê vive nos braços da mãe, vê o mudo a partir de seus braços. Se sente como tendo um grande corpo, que obedece aos seus desejos. Ele está em permanente diálogo, corpo a corpo com a mãe, ele é a mãe, esse adulto que anda. É exatamente ao redor de 3 anos, quando a mãe não vai mais colocá-lo nos braços e quando vai assumir andar com os próprios pés, que o bebê criará noções de alto e baixo, dentro e fora, e de distância, que vivenciará a grande desilusão, dando-se conta do tamanho do seu corpo e da sua fragilidade. Um grande golpe na sua autoestima, segundo Salmeron. É hora de iniciar a entrada no complexo do Édipo. O eu ideal vai permanecer e vai nos acompanhar a vida toda. Para Sônia Salmeron (1996a) o eu ideal é um pólo do ego grupal cujo antípoda é o ideal do ego, instância mais evoluída que contém nela um grupo que é formado desta admiração que a criança sente pelos diferentes adultos do seu convívio. Admiração feita de verdadeiras efusões de amor pelas realizações dos adultos. Para Salmeron (1996a), o ideal do eu é grupal na sua origem.

É através dessa organização interna grupal, Eu grupal, que a criança vai poder sair do estado de fusão interna com a mãe. Na sua evolução vai para o grupo, porque o grupo é atraente e não se deve esquecer que o bebê tem uma vivência grupal, porque ele era e é rodeado por um grupo de pessoas que tentam ter uma relação privilegiada com ele. Ele está inserido na rede tensional libidinal grupal. Então o bebê desde início é exposto, para Salmeron (1996b), à tentação de se dirigir ao grupo, aos membros do grupo, usufruir disso e ao mesmo tempo privilegiar a relação com a mãe e se sentir frustrado quando um ou outro está sendo impedido.

Segundo ela, conforme foi dito, o ideal do eu contém em si o grupo que é construído a partir da admiração que a criança sente pelos diferentes adultos do seu ambiente, admiração pelos reais feitos dos adultos, nem sempre ligados diretamente ao bem-estar da criança. Daí nasce o ideal do ego, que mais tarde vai evoluir para os ideais mais avançados, ligados a posições éticas, morais, para poder sustentar as vivências grupais, a função e a formação da vida coletiva. Podíamos pensar numa instância separada cuja função seria possibilitar a formação do grupo, e a inserção em grupos.

Diferentemente da posição de Salmeron (1996b), parece-me que não há necessidade de adjetivar o eu com grupal, já que é na relação com o ambiente, inserido na rede tensional libidinal grupal, tal qual ela tão bem descreveu - e com a sensibilidade que lhe é peculiar -, que o eu se constitui (Rocha, 2004).

Desde criança sempre fui envolvida com os bebês e suas mães. Quer dizer, gostava muito de cuidar dos recém-nascidos e sempre me propunha a ficar algumas horas com o nenê enquanto os pais se ausentavam. Assim, presenciei muitas cenas que ficaram gravadas na minha memória anos a fio. Os bebês continuaram a povoar minha vida de psicanalista também. Algumas situações ficaram emblemáticas e às vezes formam um conjunto que de repente toma sentido, esclarece ou traz um assunto novo.

Assim, vou narrar quatro cenas da vida cotidiana e dois da clínica psicanalítica que dizem da constituição do eu e dos vários na rede tensional libidinal grupal:

Fui visitar um casal de amigos e me levaram para buscar o netinho na escola, pois queriam que en o visse, em função das preocupacões com seu desenvolvimento. Chegando a casa encontramos a mãe do garotinho, quejáesperavapara dar o banho, tarefa à qual me juntei, por um momento. Logo, em seguida, voltei para a sala de estar, onde estavam os avós e o pai, que entretempo havia chegado. Para nossa surpresa, o netinho aparecen alegremente entre nós, nu, com o chapéu do pai que caía por cima das orelhas. A mãe vinha correndo atrás. Ele deu uma volta olimpica pela sala olhando bem para cada um de nós, absolutamente soberbo e irresistivel. Unanimemente 
decidimos apoiar essa bela exibição e explodimos em aplausos. O garotinho bateu palmas também, satisfeito com nossa colaboração no sen espetáculo. Devo dizer que nós também nos felicitamos entre nós, muito felizes com o seu desfile e com os nossos aplausos. Um mês depois, recebi uma carta da avó me comunicando que não havia necessidade de se preocupar mais com netinho: "ele está como naquele dia em que você nos visitou!"

Ao longo dos anos utilizei várias vezes nos seminários essa cena para ilustrar o aparecimento das identificações secundárias, a tríplice hélice do narcisismo e o início da instalação da função paterna. No entanto, um aspecto importante não tinha sido revelado nessa observação para mim. Só depois da cena que narrarei a seguir consegui distinguir e diferenciar o elemento que me parece precioso e imprescindível para o efeito de subjetivação na primeira infância.

Essa cena foi registrada num ambulatório de pediatria durante uma consultaprogramada do acompanhamento perinatal. Na sala estava o cinegrafista, a pediatra, a mãe e a filhinha, um bebezinho de 1 mês e 15 dias. O bebê dormia, enquanto a médica fazia perguntas de rotina à mãe falando sobre amamentação, hábitos $e$ saúde. Depois de um tanto, Clarissa começou aospoucos a abrir os olbinhos, abrir a boca, ações que chamaram a atenção da mãe e da pediatra. As duas trocaram algumas palavrinh as carinhosas com ela e mostraram-se satisfeitissimas com o biquinho que veio como resposta. Essa cena se repetiu mais uma vez e era a hora do exame físico da Clarissa. Era um dia frio e o bebê estava bem acolchoado em várias camadas de roupa. A mãe começou a tirar as roup as com muito cuidado, falava com carinho sorrindo para a filha. Clarissa aos poucos se prendeu no olhar da mãe e com certo esforço sustentou-o e focalizou o rosto da mãe. Abriu um sorriso feliz e desdentado animando-se para algo a mais. Enquanto a mãe abria num largo sorriso, continuando a falar com Clarissa essa por sua vez tentou soltar a voz, num primeiro momento sem sucesso. Após uma breve pausa estimulada pela mãe fez sua segunda tentativa de responder à conversa materna. Desta feita apareceu um timido arrulho que Clarissa decidiu não valorizar. Mas a mãe e a pediatra continuaram a falar, valorizando os esforço,s e então Clarissa soltou a voz. em vários arrulhos, riu satisfeita e quando aplateia toda entrava felizn n conversa ela olhou para a mãe, depois para a pediatra e para o cinegrafista que estava gravando aquela consulta. Todos festejaram essa primeira conversa, orgulhosos por estarem lá e por terem sido reconhecidos por Clarissa como partícipes desse importante momento. Era você, você, você e eu. Clarissa se reconhecia enquanto ser único em relação a cada um dos presentes e todos os presentes a reconbeciam e se congratulavam entre si festejando.

O que me chamou a atenção foi a idade do bebê, que só tinha 1 mês e 15 dias. Era uma garotinha que se desenvolvia bem dentro do previsto, para os padrões do crescimento e desenvolvimento. Mas ficou posto que compartilhar um feito em grupo mesmo nessa terna idade é possível e coube ao observador constatar o momento de subjetivação vindo desta celebração do acontecerpsíquico. Trarei a seguir mais um momento desse, desta vez com um menino de 4 meses, que também diz do acaso, em certo sentido, desses acontecimentos:

A tia estava cantando para o sobrinho uma canção de ninar e como ele mostrou-se, de repente, extremamente interessado, ela repetiu. Concentrado, olho no olho, ele entoava algumas réplicas, enquanto a tia cantava. Assim parecia. Então, de brincadeira, a tia decidiu parar após cada verso e dar uma pausa, abrindo assim espaço para o jovem cantor talentoso mostrar seus dotes musicais. Ele não negou o talento. Imediatamente produria algo semelhante (semelhante é um modo de dizer) a um som mal articulado, porém prolongado e com variações tonais. A tia continua repetindo a canção. A mãe, que observava a cena sentada ao lado, crescia, a olhos vistos, de satisfação e orgulho. Sem se fazer de rogada, ela entrou na cantoria e quando, num momento, se abaixou para pegar algo que cain, seu filhote a procurou com o olhar. A partir de então, toda vez que entoava a sua parte, ele passava o olhar para o rosto da mãe e depois para o da tia. Terminaram felicíssimos rindo à toa.

Essa foi a primeira vez que Thomas participou de uma brincadeira ciente dos vários ais presentes fruindo da ação em comum.

Por ter testemunhado outro momento com uma criança de 1 ano e 6 meses me permiti sugerir que tais acontecimentos têm repercussões na constituição psíquica do indivíduo. Vejamos:

Estávamos num restaurante self-service quando se juntou a nós um jovem pai com seu filhinho de 1 ano e 6 meses. Foi aquela algazarra, já que uma parte dos presentes não conbecia o menino e ficaram contentes 
com a sua presença. Ele ficou bem protegido no colo do seu pai por um bom tempo e, quietinho, observava os presentes sem falar. O pai the oferecia algumas comidinhas que foram prontamente recusadas com um movimento de cabeça. Aos poucos ele começou a mostrar interesse pelos presentes, o que foi notado pela turma mais jovem da mesa, desejosa de cuidar do pequeno. Ele rapidamente passou para o colo da jovem mais alegre que the ofereceu lápis de cor para desenhar nos guardanapos. Chamou-me a atenção o dominio que o menino tinha do lápis. Parecia uma criança de 3, 4 anos. A jovem contornou com lápis a mão dele, o que o encantou. Foram-se vários guardanapos nessa atividade. Nosso menino estava muitíssimo contente. Os gritos de alegria que se seguiam a cada desenho captaram a atenção dos presentes. Ai ele pegou o lápis e pôs a mão da jovem para desenhar-lhe o contorno. Obviamente, a assistência comentou tal audácia. Pois ele fezo contorno direitinho e quando a jovem levantou a mão do guardanapo arrancou suspiros de admiração. Os aplausos foram espontâneos e ele, contente, olhou para nós olho no olho, perfazendo a roda toda. O pai encheu-se de orgulho a olhos visto, claro. Mas o resto não ficou muito atrás. E foram-se os guardanapos da nossa e das mesas vizinhas. Na semana seguinte soube que nosso desenhista pronunciou as primeiras palavras, mas a primeira de todas se referia ao acontecido no self-service. Era o nome da jovem.

Os quatro exemplos descritos aconteceram fora do setting analítico. Os próximos que vou relatar fazem parte do trabalho cotidiano no CPPL ${ }^{2}$. Uma delas aconteceu durante as primeiras consultas que antecedem indicação terapêutica.

Na primeira consulta vieram os pais, um jovem casal simpático cheio de dúvidas e indagaçôes acerca do filhinho de 2 anos que, segundo eles, estava apresentando algumas dificuldades no desenvolvimento. Eles estavam muito receosos e foram pressionadospelos familiares a consultar um especialista. No fim da conversa apareceu o medo de receberem o diagnóstico de autismo, apesar de a mãe ter se informado na internet e ter chegado à conclusão de que o filhote pouco correspondia às descrições dessa patologia. Propus então de vê-los novamente, junto com a criança. Conversei com uma colega e pedipara juntar-se a nós durante a consulta; caso precisasse empreender uma psicoterapia em grupo ou individualmente, ela estaria já em contato com os pais e a criança. Marcelo chegou com os pais e subimos para o atendimento. Ofereci os brinquedos, que ele espalhou pelo meu divã. Muito atento à conversa dos adultos, virava-se para mostrar algum brinquedo ao pai. Quando a colega chegou, sentou-se, após apresentada, no cantinho do divã, próxima a Marcelo. Ele não deu muita atenção, então ela pegou um pequeno dinossauro e foi se aproximando sem nada dizer. A chegada do dinossauro, ao contrário, foi percebida imediatamente e o brincar agora correu solto. Muito entretido, Marcelo apenas se virava de vez. em quando para o pai, lançando uma rápida olhada. Fui buscar um brinquedo e na volta dei uma tropeçada no pé de Marcelo, que estava ajoelhado ao lado do divã. Levei um susto e dei um pulo para não machucá-lo. Ele olhou e riu, eu também ri, pedindo desculpas e nós caímos na gargalhada. Era muito engraçado tudo isso. Marcelo girou e olhou para o pai, para minha colega e para mim, por último para a mãe. Eles também acharam graça. Era hora de compartilhar. Enfim estávamos todos juntos.

Essa cena, como as outras, teve um desfecho satisfatório. Os pais se convenceram de que uma criança que interage com tanta espontaneidade com certeza não pode receber o diagnóstico de autismo infantil. Eles de fato não estavam convictos desse diagnóstico, nem o haviam recebido de ninguém, estavam apenas com muito medo. Assim, se tranquilizaram, puderam reconhecer que o filho de fato tinha um atraso no desenvolvimento da linguagem e, ao lado de uma irmã muito falante e espaçosa, recuava, ficando em segundo plano. A indicação terapêutica foi bem aceita e a participação deles no tratamento do filho facilitou o nosso trabalho, que terminou com êxito.

Mais uma cena, dessa vez para ilustrar um acontecer psíquico do Eu construindo a experiência da coletividade e sua inscrição na história do indivíduo, numa sessão de psicanálise em grupo, com crianças entre 2 e 4 anos:

Jorge estava no grupo havia cinco meses, quando recebemos uma visita. $N$ a sala de grupo, nosso colega psicanalista ocupou bastante espaço pelo seu tamanho. Sentou-se num canto e ficou observando enquanto nós

2 CPPL: Centro de Pesquisas em Psicanálise e Linguagem, instituição terapêutica para crianças com sede em Recife. 
comeşávamos a brincar. Jorginho, com os olhos grudados no nosso visitante, foi para baixo da mesa, de onde espiava esse grandalhão que surgiu assim de repente no grupinho. Aquele tiquinho de gente de olhos azuis ficou deslumbrado e cheio de vontade de contar algo para ele e paranós. Ele ensaiou oprimeiro aparecimento por cima da mesa apenas com um grande sorriso e com os olhos grudados no colega que, entretido com o que acontecia do outro lado da sala, não percebeu esse convite para conversa. Jorginho desapareceu por baixo da mesa e depois de alguns segundos reapareceu com um sorriso e um grito pouco articulado. Assim conseguiu apenas chamar a atenção de um dos terapentas, que então entrando na brincadeira gritou: "apareceu!" Jorginho, não satisfeito, mergulhou porbaixo da mesa e emergiu de novo, agora batendopalmas. Definitivamente, os esforços eram dirigidos para o nosso visitante, que a essa altura afinal prestou atenção no Jorginho, que, satisfeito que nem pintinho na lama, desapareceu para reaparecer. A essa altura todo o grupo, junto com o colega, estava devidamente alerta e prestes a completar a brincadeira. Quando o Jorginho apareceu, olhou para cada um de nós e, é claro, no primeiro momento, para nosso amigo, alvo dos seus esforços; enquanto nós aplaudiamos e gritávamos "apareceu!". Ele disse, então, solenemente: "eu!". Seguiu-se aquele carnaval de alegria e depois todas as crianças foram para baixo da mesa e assim se foi até o termino da sessão.

Os seis exemplos em diferentes momentos e diferentes idades das crianças mostram o acontecer psíquico do "Eu". Em seis cenas, em diferentes idades, as crianças compartilharam uma coisa que foi feita por eles, reconhecida pelo grupo, mas o reconhecimento que as crianças fizeram era distinguir cada um individualmente, se dirigindo a cada um pelo olhar, e celebrando no olhar do outro a satisfação que elas mesmas tiveram com o que tinham feito. Quer dizer, mesmo o bebê de um 1 e 15 dias se reconheceu como pessoa em relação a cada um ali presente no ambulatório, e cada um do grupo, além de compartilhar com os outros adultos do grupo, celebrou sua participação naquele acontecimento e reconheceu-se como indivíduo em relação àquele bebê. No caso de Thomas, com quatro meses, seu olhar reconhecia cada um e se reconhecia no olhar do outro. Mas o mais importante de tudo era ver que a mãe e a tia o viam olhando-as. É esse movimento mencionado antes no texto que denomino brincando de "tríplice hélice do narcisismo". O movimento da hélice ofertará a dinâmica necessária para celebração de acontecer psíquico do eu, para celebração desse momento de diferenciação e reconhecimento dos vários, onde a realização de uma ação é peremptória.

É nesse sentido que posso dizer que esses são os momentos da constituição do eu, pelainserção na rede tensional libidinal grupal, onde não sou eu e vocês (totalidade), não somos nós (massa), mas você, você, você e eu (vários). Um grupo que faz algo em conjunto, mas onde cada um que participa tem noção do conjunto da diversidade e reafirma sua singularidade na ação.

A noção da responsabilidade para consigo e para com os outros no fazer acontecer e a celebração da produção coletiva em seus vários aspectos subsumidos aí estão já postas para o futuro.

Acontecem, para muitos de nós, ao longo da nossa existência, momentos como esses narrados neste texto que fazem para nós o que Joel Birman (2001) anunciou no fim da apresentação do livro Autismos: "Afinal, o que está em questão aqui, pois, é a invenção da gramática do impossível, 'fiat lux do fazerviver". Às vezes acho que as seis cenas que narrei testemunham este "fiat lux" do acontecer psíquico tal qual imaginou Freud.

No decurso de trinta anos de trabalho no CPPL tratamos de ampliar e formular na medida do possível nosso conhecimento sobre a constituição psíquica, para enriquecer nossa prática psicanalítica institucional com as crianças cujo sofrimento psíquico precoce as tornou singulares ao ponto de saltarem aos olhos, tão visíveis na sua diversidade, que findaram negadas enquanto pessoas (Cavalcanti \& Rocha, 2001). Propor cuidare deixar-se implicar nessa clínica exige disponibilidade e vitalidade psíquica para o encontro com o inusitado, imprevisível, mas sobremaneira reitera a humildade na espera do acaso.

Para tanto, se faz necessário compartilhar a longa espera, os percalços e sobressaltos, é preciso vários, requer uma equipe. Emprestar a sua privacidade para que o outro encontre ou reencontre a sua própria, como diz André Green (1977), com essas crianças pressupõe enredar-se numa proximidade que necessita de vários, semelhantes e confiáveis, presentes para sustentar a distância psíquica e tornar possível o acontecer psíquico do qual falamos. A formação da rede tensional libidinal grupal está na base de nosso trabalho e é mais perceptível na psicanálise em grupo com as crianças. Na medida em que conseguimos sustentá-la na relação entre 
os terapeutas e em relação a cada criança, tornamos possível o tal "flat lux do fazer viver". Sem garantias, mas é uma possibilidade.

Muitas vezes só percebemos quando já aconteceu, como no dia em que Roberto chegou à porta do meu consultório e disse: "bom dia, tia Paula". E de fato estava lá Roberto em carne e osso, habitando si mesmo, simplesmente bem. Fazia tempo que Roberto estava falante, leitor incansável dos gibis, afeiçoado aos jogos eletrônicos, crítico feroz das minhas parcas capacidades nesses últimos. Mas mesmo assim Roberto não estava ali. Conversava, mas não estava. Até o dia em que chegou e continuou. São horas em que a equipe celebra. Para celebrar tem que ser você, você, você e eu. "Eu quero" de Roberto não tardou. Mas no dia em que Roberto afinal compareceu, eu devia ter lhe dito:

"Carpe Diem, Roberto!"

\section{REFERÊNCIAS}

Anzieu, D. (1976). L'enveloppe sonore du soi. Nouvelle Revue de Psychanalyse, (13), 54-68.

Birman, J. (2001). Apresentação. In A. E. Cavalcanti, \& P. S. Rocha. (Org.). Autismos (pp. 10-24). São Paulo: Escuta.

Cavalcanti, A. E., \& Rocha, P. S. (2001). Autismos. São Paulo: Escuta.

Freud, S. ([1911] 2004). Formulações sobre os dois princípios do acontecer psíquico. In S. Freud. Escritos sobre a psicologia do inconsciente (Luiz Alberto Hanns, Trad.). Rio de Janeiro: Imago.

Freud, S. ([1920] 1996). Psicologia das massas e análise do ego. In S. Freud. Edição Standard das Obras Completas de Sigmund Freud (pp. 295-300). Rio de Janeiro: Imago.

Green, A. (1977). O outro e a experiência de "self". In M. Khan. Psicanálise: Teoria, técnica e casos clínicos (pp. 285-304). Rio de Janeiro: Francisco Alves.

Kaës, R. (1976). L'appareil psychique groupal, construction du groupe. Paris: Dunod.

Klein, M. (1981). Contribuições à psicanálise. São Paulo: Mestre Jou.
Kupfer, M. C., Jerusalinsky, A. F., Bernardino, L. F., Wanderley, D., Rocha, P. S., Molina, E. S., et al. (2009). Valor preditivo de indicadores clínicos de risco para o desenvolvimento infantil: Um estudo a partir da teoria psicanalítica. Lat Am Journal of Fund Psychopath, 6(1), 48-68, 2009.

Rocha, P. S. (2004). Você, Você, Você, e Eu. Trabalho apresentado no $\mathrm{X}$ Encontro Psicanalítico do CPPL: Novos temas em Psicanálise. Recife: [s.n].

Salmeron, S. (1996a). Moi grupal. In Séminaires sur les concepts de base de la psychothérapie psychanalytique d'enfants et d'adultes. Paris: Centre Alfred Binet.

Salmeron, S. (1996b). Réseau libidinal tensionnel. In Séminaires sur les concepts de base de la psychothérapie psychanalytique d'enfants et d'adultes. Paris: Centre Alfred Binet.

Winnicott, D. W. (1978). A família e o desenvolvimento do indivíduo. Belo Horizonte: Interlivros.

Recebido: 21/03/2009

Received: 03/21/2009

Aprovado: 04/07/2009

Approved: 07/04/2009 